$$
\text { CONF-971048--5 }
$$

BNL- 64590

\title{
ADVANCED BIOCHEMICAL PROCESSES FOR GEOTHERMAL BRINES CURRENT DEVELOPMENTS
}

E.T. Premuzic ${ }^{1}$, M. S. Lin ${ }^{1}$, M. Bohenek ${ }^{1}$, V. Bajsarowicz ${ }^{2}$, and M. McCloud ${ }^{3}$

${ }^{1}$ Energy Science and Technology Division

Department of Applied Science

Brookhaven National Laboratory

Upton, NY 11973

${ }^{2}$ CET Environmental Services, Inc.

Richmond, CA 94806

${ }^{3}$ C.E. Holt/California Energy

Pasadena, CA 91101

July 7, 1997

To be presented at the Geothermal Resources Council

1997 Annual Meeting

San Francisco, CA

October 12-15, 1997

DISTAIBUTION OF THIS DOCUMENT IS UMLMITED

This research was performed under the auspices of the U.S. Department of Energy under Contract No. DE-AC02-76CH00016. 


\section{DISCLAIMER}

This report was prepared as an account of work sponsored by an agency of the United States Government. Neither the United States Government nor any agency Thereof, nor any of their employees, makes any warranty, express or implied, or assumes any legal liability or responsibility for the accuracy, completeness, or usefulness of any information, apparatus, product, or process disclosed, or represents that its use would not infringe privately owned rights. Reference herein to any specific commercial product, process, or service by trade name, trademark, manufacturer, or otherwise does not necessarily constitute or imply its endorsement, recommendation, or favoring by the United States Government or any agency thereof. The views and opinions of authors expressed herein do not necessarily state or reflect those of the United States Government or any agency thereof. 


\section{DISCLAIMER}

Portions of this document may be illegible in electronic image products. Images are produced from the best available original document. 


\title{
ADVANCED BIOCHEMICAL PROCESSES FOR GEOTHERMAL BRINES: CURRENT DEVELOPMENTS
}

\author{
Eugene T. Premuzic, Mow S. Lin, and Michael Bohenek \\ Energy Science and Technology Division \\ Brookhaven National Laboratory
}

Voytek Bajsarowicz

CET Environmental Services, Inc.

Mary McCloud

C.E. Holt/California Energy

\begin{abstract}
A research program at Brookhaven National Laboratory (BNL) which deals with the development and application of processes for the treatment of geothermal brines and sludges has led to the identification and design of cost-efficient and environmentally friendly treatment methodology. Initially the primary goal of the processing was to convert geothermal wastes into disposable materials whose chemical composition would satisfy environmental regulations. An expansion of the R\&D effort identified a combination of biochemical and chemical processes which became the basis for the development of a technology for the treatment of geothermal brines and sludges. The new technology satisfies environmental regulatory requirements and concurrently converts the geothermal brines and sludges into commercially promising products. Because the chemical composition of geothermal wastes depends on the type of the resource, the emerging technology has to be flexible so that it can be readily modified to suit the needs of a particular type of resource. Recent conceptional designs for the processing of hypersaline and low salinity brines and sludges will be discussed.
\end{abstract}

\section{BACKGROUND}

World electric power generation in 1994 was 7772 billion $\mathrm{kW} / \mathrm{hr}$ of which 109.5 billion $\mathrm{kW} / \mathrm{hr}$ was from geothermal resources or $1.4 \%$ worldwide. In the USA alone, geothermal resources contributed $3.1 \%$, therefore higher than worldwide average (Grillot, 1996). Compared to coal and oil, geothermal energy is a clean source of electric power and its use worldwide is increasing (e.g. Freeston, 1996). However, on cooling of the hot high saline brines, a sludge is produced which is considered a mixed waste and, therefore, subject to regulatory constrains. Processing of low salinity liquids produces a chemically different residue, disposal of which is also regulated. The latter type of byproduct is associated with the Geyser type steam condensates and the former with the Salton Sea type brines.

Biochemical treatment of geothermal brines involves a ten variable process (Premuzic et al., 1996a; Premuzic et al., 1996b). Optimization of these variables led to the design of a process in which two biocatalysts are used in $85 \%$ to $15 \%$ proportions. This conceptual design processes $1300 \mathrm{Kg} / \mathrm{h}$ of geothermal sludge generated from hypersaline resources. The end product in this process is a $1200 \mathrm{Kg} / \mathrm{h}$ cake from which toxic and valuable metals, originally present in the starting material, have been removed. The produced residue meets regulatory requirements (Royce, 1985) and can be disposed of as a non-regulated waste. The filtrate, which now contains toxic and valuable metals, is neutralized with lime and filtered. The neutralized cake can be further treated for the recovery of valuable metals such as gold which is present in ppm quantities (see also next section) and the filtrate can be re-injected into a well. In this process, the kinetics of metal solubilization are fast ( $<8$ hours per batch) with solubilization efficiencies of better than $85 \%$ for all of the metals of interest (e.g. arsenic, zinc, gold, chromium, copper, etc.). Because of the differences in the chemical nature of the geothermal resource and the residues generated in the production of power from low salinity geothermal liquids, the overall biochemical process had to be modified. Thus in the Geysers-type geothermal waste, one is dealing with a sulfur cake contaminated with iron, some silica, arsenic, and mercury. Initially, two treatment scenarios have been considered. In the first scenario, a slurry is treated with two biocatalysts. This treatment yields a residue of crude sulfur and an aqueous phase containing arsenic and mercury. The aqueous phase can be re-injected. In the second scenario, the sulfur is first extracted with a solvent, yielding a high grade sulfur product. The residue, after the removal of sulfur, is then treated as described in the first scenario. Because of regulatory restrains, the solvent extraction scenario was abandoned. 
Follow-up R\&D allowed the exploration of several alternatives. Extended research and further optimization of the processes for the treatment of residues produced in the generation of geothermal power from high and low salinity brines has made possible additional potential cost savings and simplifications in the design of the technology. The results of this research and development effort will be briefly discussed in the next section.

\section{RECENT ACTIVITIES}

Analysis and re-evaluation of the original process design (Premuzic et al., 1996a; Premuzic et al., 1996b) for the treatment of sludges produced from high salinity geothermal resources enabled further simplification and improvements of the process. This effort led to recommendations for the modification of the three major steps in the process: (1) the use of one instead of two biocatalysts; (2) avoidance of the lime neutralization; and (3) processing of the silica filter cake. Changes in these three steps, a combination of biochemical and chemical processing, and the use of available reagents added further improvements and potential cost savings. Thus, the use of a single biocatalyst proved to be possible. Further, re-processing of the silica filter cake into a high quality silica, which can be used as a filler, coupled with recycling and re-injection as well as metal recovery options resulted in the process summarized in Figure 1.
The process shown in Figure 1 also indicates potential profits that may be generated from valuable metals and salt recovery options. The profits are projections based on current market values. Figure 2 shows a conceptual flow sheet for the processing of $500 \mathrm{Kg} / \mathrm{h}$ of a hypersaline sludge. This process assumes the use of a single biocatalyst, recyclable water, and aqueous chemical reagents. The economic significance of such a processing scenario based on laboratory pilot plant and modeling data is shown in Table 1. The profitability of the process was estimated by using standard chemical engineering design procedures (Ulrich, 1984). Field demonstration strategies for these processes are currently being explored.

Re-evaluation of the processing of sludges produced in the production of geothermal power from low salinity liquids has led to similar improvements. However, to accomplish this, certain variations had to be taken into consideration. The chemistry of geothermal sludges changes on storage. Further, in the case of sludges generated at Geysers, the biochemical solubility of mercury is less then that of arsenic. Thus, the initial biochemical treatment solubilizes arsenic and mercury. However, while a better than $80 \%$ solubilization of arsenic renders a product well within the total threshold limit concentrations (Royce, 1985) for arsenic, it does not do so for mercury. Also, on standing the solubility of mercury appears to decrease, while that of arsenic does

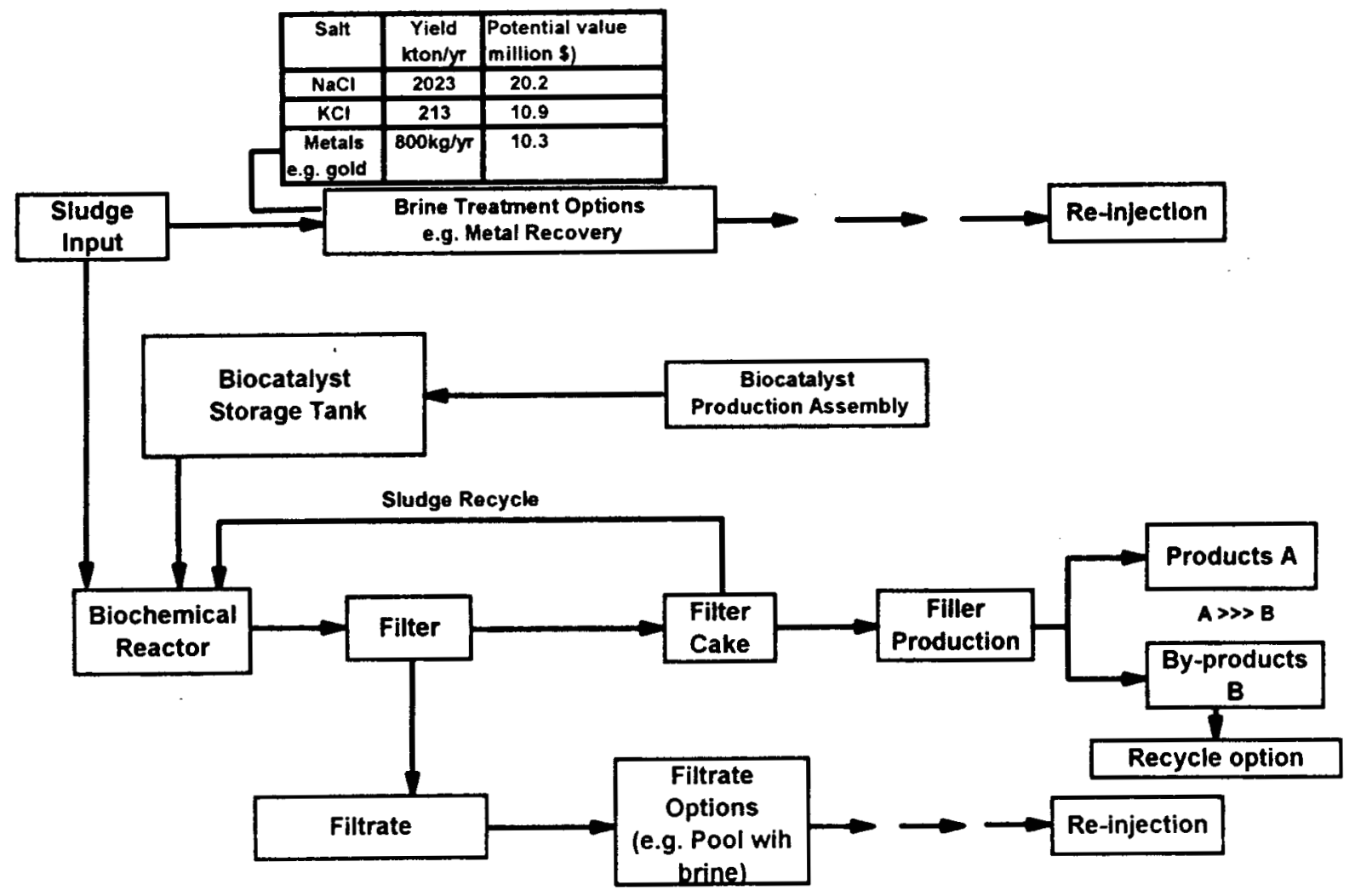

Figure 1. Total processing of geothermal sludges \& brines 


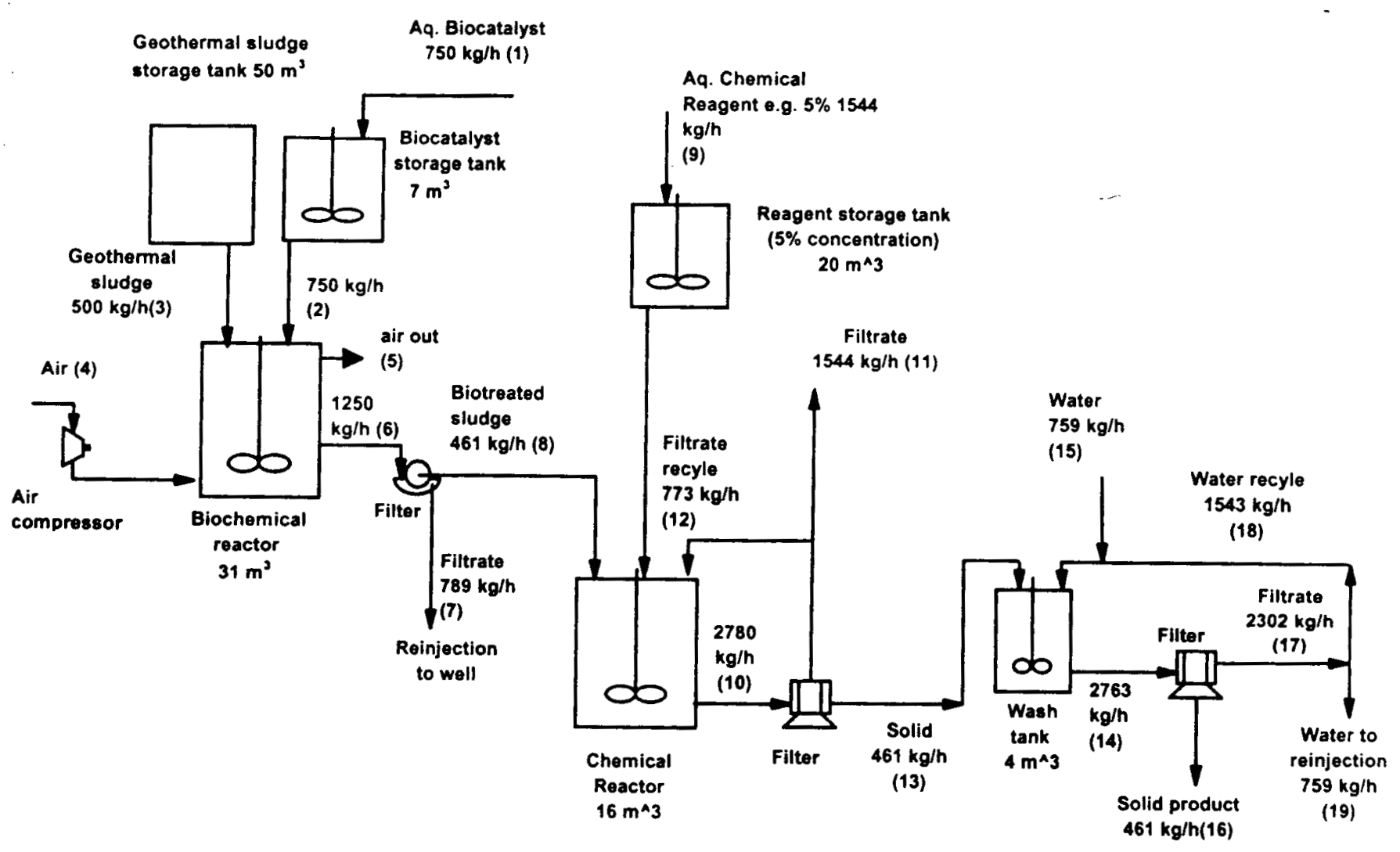

Figure 2. Conceptual process flowsheet for the treatment of geothermal sludges $500 \mathrm{~kg} / \mathrm{hr}$

Table 1. Filler production from geothermal brines cost analysis of process changes

\begin{tabular}{|l|c|c|c|}
\hline & $\begin{array}{c}\text { Original Case } \\
\text { Two Biocatalysts }\end{array}$ & $\begin{array}{c}\text { Second Case } \\
\text { One Biocatalyst }\end{array}$ & $\begin{array}{c}\text { Third Case } \\
\text { One Biocatalyst and a } \\
\text { Chemical Reagent }\end{array}$ \\
\hline $\begin{array}{l}\text { Capital Investment (thousands of } \\
\text { dollars) }\end{array}$ & 4080 & 3606 & 3606 \\
\hline $\begin{array}{l}\text { Total Expenses (thousands of } \\
\text { dollars per year) }\end{array}$ & 6751 & 6652 & 2980 \\
\hline $\begin{array}{l}\text { Revenue from filler sales and } \\
\text { savings from avoiding waste } \\
\text { disposal (thousands of dollars per } \\
\text { year) }\end{array}$ & 16517 & 16517 & 16517 \\
\hline $\begin{array}{l}\text { After tax net profit (thousand of } \\
\text { dollars per year) }\end{array}$ & 6347 & 6412 & 8799 \\
\hline $\begin{array}{l}\text { After tax rate of return on } \\
\text { investment \% }\end{array}$ & 164 & 186 & 253 \\
\hline
\end{tabular}


not (Garriques, Hayden, 1997). The first evidence that changes in the chemical speciation of mercury may occur has been observed in experiments dealing with the solvent extraction of sulfur (Premuzic et al, 1996b) where a reduction of about $50 \%$ in solubility relative to arsenic has been observed under identical experimental conditions. In view of these results, an alternative processing strategy for the Geysers type sludges has been developed. In this process, a single biocatalyst is used and the sulfur cake is converted into high grade sulfur (Figure 3). This sulfur is produced by conventional sublimation technology which does not involve any solvent extraction steps. The light powdered residue produced in the sublimation step (B, Figure 3) consists predominantly of iron $(>92 \%)$ and small amounts of arsenic, alumina, mercury, and magnesium. Residue B is a byproduct of a $90 \%$ volume reduction of the starting material. In the current process design (Figure 4) residue $B$ is slurried and re-injected with the arsenic bearing aqueous phase generated in this process. Agricultural and other applications of the sublimed sulfur, produced in this process, are currently being explored.

\section{CONCLUSIONS}

1. Compared to mixed waste disposal and liability costs a combination of biochemical and chemical technology for the treatment of geothermal brines and sludges is cost-efficient and yields commercially viable byproducts.

2. The emerging technology minimizes wastes and utilizes available recycling options.

3. Close collaboration and partnering between BNL and industry enables a full development and field applications of the emerging technology.

\section{ACKNOWLEDGMENTS}

This work has been supported by the U.S. Department of Energy, Office of Conservation and Renewable Energy, Geothermal Technology Division, Washington, DC under Contract No. AM-35-10 and by Brookhaven National Laboratory with the U.S.

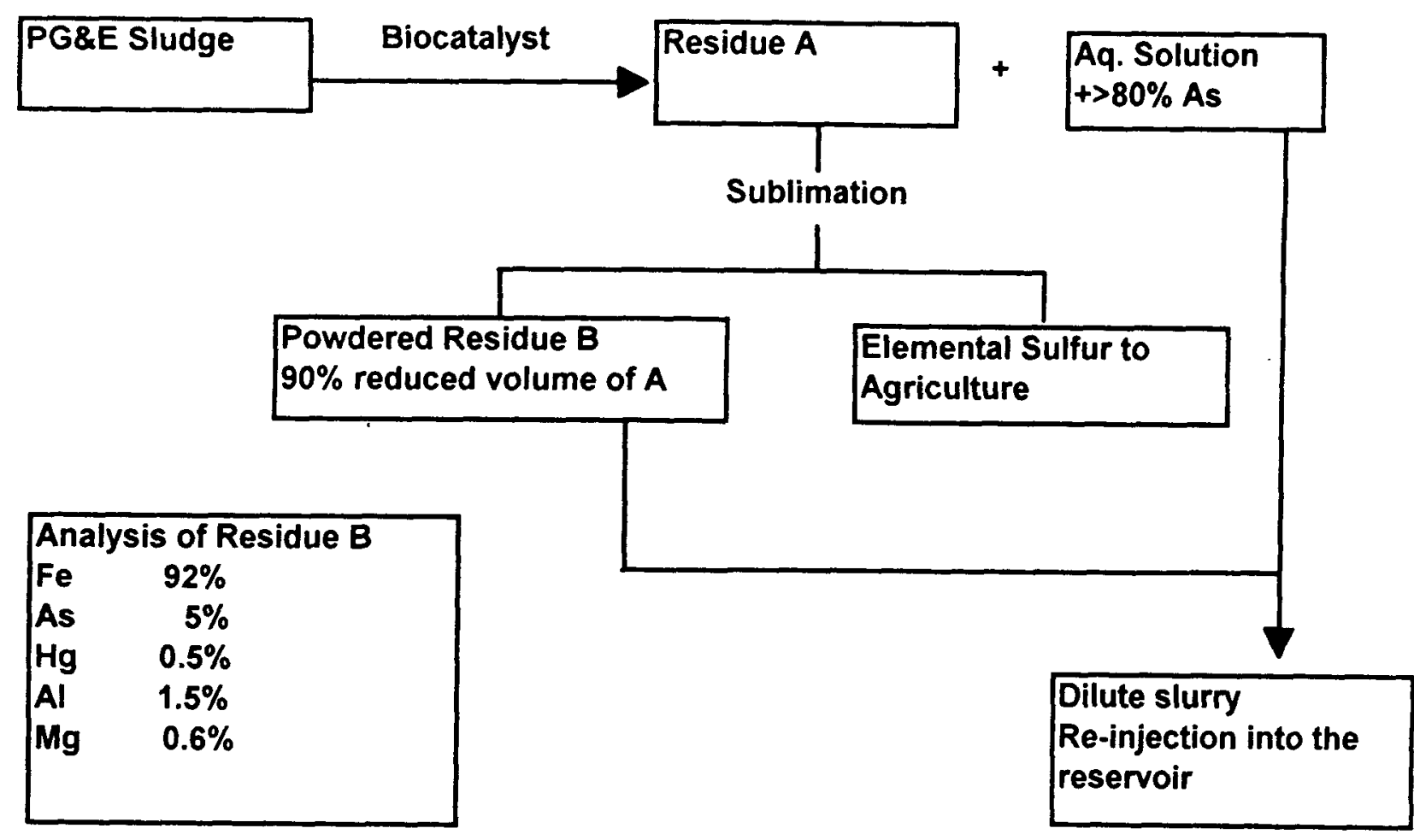

Figure 3. The overall simplified process for Geyser-type geothermal sludges 


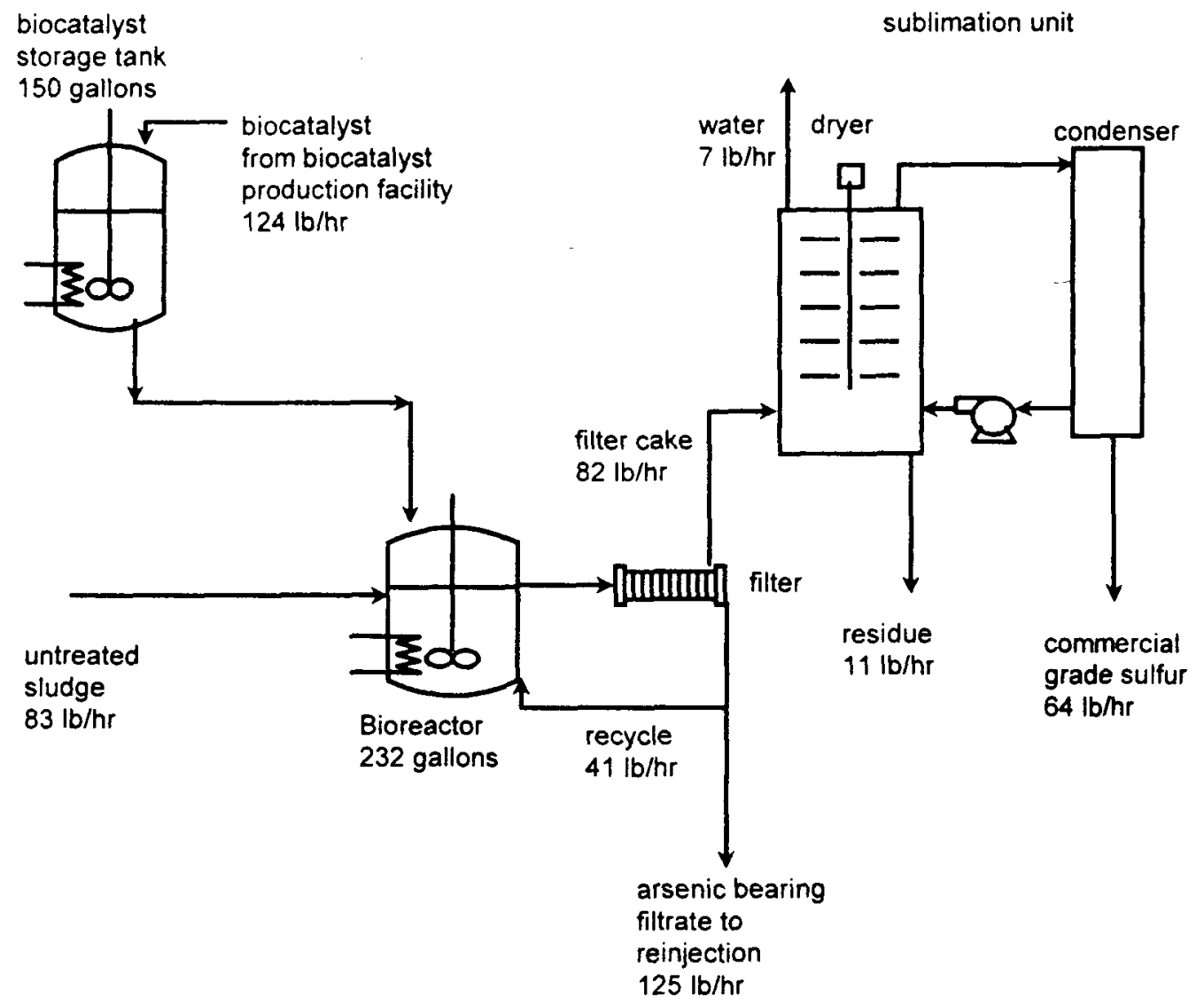

Figure 4. Conceptual process flowsheet for treatment of Geyser-type geothermal sludges

Department of Energy under Contract No. DE-AC0276CH00016. We also wish to express our gratitude to W.M. Zhou, J. Yablon, and K. Mantione for technical assistance and Ms. Gladys Hooper, the U.S. DOE program manager, for continuous interest and encouragement.

\section{REFERENCES}

Freeston, D.H., 1996. "Direct Uses of Geothermal Energy," Geo-Heat Center Quarterly Bulletin, Vol. 17, No. 1, ISSN: 0276-1084.

Garriques, Hayden, 1997. M.S. Thesis, Howard University/Brookhaven National Laboratory, University Program Graduate Studies, in preparation.

Geothermal Energy, Earth Science Laboratory, University of Utah Research Institute, Salt Lake City.

Grillot, M.J., 1996. International Energy Annual, Energy Information Administration, Washington, D.C., Chapter 6.
Premuzic, E.T., M.S. Lin, and H. Lian, 1996a. "Geothermal Brines and Sludges: A New Resource," Environmental Issues and Waste Management in Energy and Mineral Production, Proceedings of SWEMP '96, Cagliari, Italy, Fourth International Conference, 2, pp. 10191025.

Premuzic, E.T., M.S. Lin, and H. Lian, 1996b. "Recent Advances in Biochemical Technology for the Processing of Geothermal Byproducts," Proceedings of the Geothermal Program Review XIV, DOE/EE-0106, pp. 135-144.

Royce, B.A., 1985. "An Analysis of Environmental Regulations Governing the Disposal of Geothermal Wastes in California," BNL Informal Report No. 375077 .

Ulrich, G.D., 1984. "A Guide to Chemical Engineering Process Design and Engineering," John Wiley \& Sons, New York. 